\title{
Effects of histamine, ethanol, and a detergent on exudation and absorption across guinea pig airway
} mucosa in vivo

\author{
Lennart Greiff, Ingrid Erjefält, Per Wollmer, Ulf Pipkorn, ` Carl G A Persson
}

\begin{abstract}
This study examined effects of three substances that cause mucosal provocation (histamine, ethanol, and the detergent dioctylsodium sulphosuccinate (DOSS)) on the flux of solutes across airway vascular mucosal barriers in anaesthetised guinea pigs. The inward flux was assessed as absorption of iodine-131 labelled albumin (MW 69000 ) from the tracheobronchial surface into the circulation and the outward flux as the exudation of two intravenously administered plasma tracers- ${ }^{125} I$ albumin (MW 69000 ) and fluorescein isothiocyanate conjugated (FITC) dextran (MW 70000 )-into the airway. The absorption of technetium99m labelled DTPA (MW 492) from the tracheobronchial airways was determined in separate experiments. Histamine $(5.0 \mathrm{nmol})$ dissolved in $40 \mu \mathrm{l}$ saline and superfused on to the tracheobronchial mucosal surface caused significant and similar entry of ${ }^{125} I$ albumin and
\end{abstract} FITC dextran into the airway lumen. This dose of histamine did not, however, alter the absorption of small ${ }^{99 \mathrm{~m}} \mathrm{Tc}$ DTPA) or large ( ${ }^{131} \mathrm{I}$ albumin) solutes across the airway mucosa. Ethanol (0.17 $\mu \mathrm{mol})$, superfused in the same way, also caused significant exudation of the plasma tracers into the airway lumen. In addition, ethanol increased the absorption of ${ }^{131} I$ albumin without causing change in the disappearance rate of ${ }^{99 \mathrm{~m}} \mathrm{Tc}$ DTPA. The detergent, DOSS (0.28 nmol $)$, dissolved in ethanol $(0 \cdot 17 \mu \mathrm{mol})$, caused a pronounced increase in exudation and much increased absorption of small and large tracer solutes. Thus three patterns of change in airway mucosal barriers were found. The agents that are toxic to membranes, ethanol and DOSS, caused a bidirectional increase in permeability across the mucosa, whereas histamine caused only an outward exudative flux. The results obtained with histamine are similar to those seen previously with bradykinin, capsaicin, and allergen, suggesting that endogenous inflammatory mediators have a role in mucosal defence, producing entry of plasma exudates into the airway lumen without increasing the mucosal absorption of luminal material.
Plasma exudation may occur in asthma and contribute to the pathogenesis of the disease. ${ }^{1}$ We have previously shown that inflammatory provocation of the guinea pig tracheobronchial mucosa causes prompt exudation of plasma into the airway tissue and lumen. ${ }^{23}$ The entry of substantial amounts of large solutes from plasma into the lumen shows that the exudation permeability of the epithelial lining has greatly increased. It is widely believed that such changes in epithelial permeability are bidirectional and hence that increased exudation is associated with increased absorption of luminal material across the epithelium. ${ }^{47}$ Recent in vivo and in vitro observations in guinea pig airways, however, suggest that the changes associated with inflammation are predominantly exudative. ${ }^{89}$ Mucosal challenge with allergen, bradykinin, and capsaicin caused a 15-20 fold increase in the luminal content of plasma tracers with no concomitant increase in the absorption of tracer molecules from the airway lumen. ${ }^{9}$ Data obtained in vitro suggest that the unidirectional flux of macromolecular solutes into the airway lumen may be via hydrostatic pressure operated valve like passages between epithelial cells. ${ }^{111}$ Morphological and functional data also suggest that after exudation of unfiltered plasma into the lumen the epithelial lining promptly resumes its normal tightness. ${ }^{8-13}$

Data from nasal studies in man also support these findings. Svensson et al ${ }^{14}$ found that the nasal mucosa responded to repeated histamine applications with a reversible and repeatable exudative response even when the interval between the histamine applications was as short as 30 minutes. Greiff et al ${ }^{15}$ showed that the change in mucosal permeability was unidirectional as the absorption of chromium51 labelled EDTA (MW 372) across the mucosa was not increased with prolonged histamine induced exudation. Entry of a plasma exudate into the airway lumen should be considered as a first line defence mechanism of the normal mucosa, ${ }^{8}$ in view of the prompt response to provocation and the non-injurious and unidirectional nature of the process. ${ }^{391115}$

In this study we have determined plasma exudation and mucosal absorption of solutes in guinea pig airways, using different topical provocations. Histamine was examined to see if it produced an increase in exudation with no increase in solute absorption, as observed with bradykinin, the neurogenic stimulus cap- 
saicin, and an $\mathrm{IgE}$ driven allergic reaction. ${ }^{9}$ The effects of histamine were compared with those of a detergent, dioctylsodium sulphosuccinate (DOSS), and its vehicle, ethanol. DOSS is likely to increase the absorption permeability of the airway mucosa, but its effect on plasma exudation is unknown. As previous studies in guinea pig tracheobronchial airways had examined only macromolecular absorption, we studied the absorption of both a large (iodine-131 labelled albumin, MW 69000 ) and a small (technetium-99m labelled DTPA, MW 492) luminal solute.

\section{Methods \\ STUDY DESIGN \\ We examined the outward (exudation) and inward (absorption) permeability of the vas- cular mucosa airway barriers after mucosal provocation with histamine $(5.0 \mathrm{nmol})$, ethanol $(0.17 \mu \mathrm{mol})$, and DOSS $(0.28 \mathrm{nmol})$ plus ethanol $(0.17 \mu \mathrm{mol})$. Fluorescein isothiocya- nate conjugated dextran (FITC dextran, MW 70000 ) and ${ }^{125} \mathrm{I}$ albumin (MW 69000 ) were administered intravenously as plasma tracers. ${ }^{131} \mathrm{I}$ albumin (MW 69000 ) and ${ }^{99 \mathrm{~m}} \mathrm{Tc}$ DTPA (MW 492) were superfused on to the tracheal mucosal surface as large and small solute $a b-$ sorption tracers respectively in separate groups of animals.}

\section{PREPARATION OF ANIMALS}

Male guinea pigs weighing about $400 \mathrm{~g}$, and with a normal weight gain during 10 days' observation, were used. After starvation for four hours the animals were anaesthetised with a $3: 2$ mixture of ketamine $(50 \mathrm{mg} / \mathrm{ml})$ and xylazine $(20 \mathrm{mg} / \mathrm{ml}) 1.0 \mathrm{ml} / \mathrm{kg}$ intramuscularly. These drugs maintain stable anaesthesia during experiments and exert little effect on arterial blood pressure. ${ }^{16}$

To prepare for tracheal superfusion, a thin plastic tube (outer diameter $0.6 \mathrm{~mm}$ ) was introduced into the proximal tracheal lumen via the moùth and positioned with its tip about $1 \mathrm{~cm}$ below the larynx. ${ }^{3}$ The tracheal catheter was connected to a servo pump and the animals were inclined at a $45^{\circ}$ angle (head up) to facilitate tracheobronchial distribution of the superfusate.

\section{PLASMA EXUDATION AND ABSORPTION OF \\ ${ }^{131}$ I ALBUMIN \\ Intravenous administration of plasma tracers}

Ten minutes after tracheal catheterisation the plasma tracers FITC dextran $(5 \%)$ in saline $(0.25-0.30 \mathrm{ml} / 100 \mathrm{~g})$ and ${ }^{125} \mathrm{I}$ albumin (about $0.5 \mathrm{MBq})$ in saline $(0.025-0.05 \mathrm{ml} / 100 \mathrm{~g})$ were administered via a marginal vein in the ear.

\section{Tracheobronchial administration}

Ten minutes after the administration of plasma tracers the surface of the tracheal mucosa was superfused with solutions $(40 \mu \mathrm{l})$ delivered at a constant rate over two minutes. The absorption tracer ${ }^{131} \mathrm{I}$ albumin (about $20 \mathrm{kBq}$ ) was given with histamine $(5.0 \mathrm{nmol})$, ethanol $(0 \cdot 17 \mu \mathrm{mol})$, and DOSS $(0.28 \mathrm{nmol})$ plus ethanol $(0 \cdot 17$ $\mu \mathrm{mol})$, or saline control. All solutions contained guinea pig albumin $(3.0 \mathrm{mg} / \mathrm{ml})$.

After completion of the superfusion the tracheal catheter was withdrawn. The animals were kept in the same position for a further five minutes and then placed on a heating pad in the horizontal position for five minutes. Each treatment group contained six animals. Two samples $(40 \mu \mathrm{l})$ of the superfusion solution were obtained as standards and counts were made on them at the same time as those on the tissue and plasma samples from each animal.

\section{Termination of the experiments}

The experiments were terminated by intravenous administration of pentobarbital (60 $\mathrm{mg} / \mathrm{ml}$ ) $0.2 \mathrm{ml}$. A thoracotomy was performed and a mixture of arterial and venous blood was collected through an incision made into the ventricles of the beating heart. After addition of heparin the samples were centrifuged $(500 \mathrm{~g}$, six minutes) to separate the plasma.

\section{Tracheal lavage}

The trachea was lavaged as previously described and validated. ${ }^{3}$ Briefly, the larynx, trachea, and lungs were excised en bloc. The preparation was arranged in a tilted position with the larynx upwards and the lobar bronchi were tied with ligatures at the hilar level. A plastic tube was introduced through an incision in the left principal bronchus and secured by a ligature. The mucosal surface of the lower portion of the trachea was irrigated through this tube by four retrograde superfusions over one minute with $0.25 \mathrm{ml}$ saline. The lavage fluid was readily visible through the thin tracheal wall; the fluid was infused to $1 \mathrm{~cm}$ below the level where the tracheal tube had been positioned.

\section{Tracheal tissue sampling}

The trachea was cleaned macroscopically from external vessels and lymph nodes. A section of the superfused and lavaged intrathoracic part of the trachea was excised for tracer analyses.

\section{Analyses of exuded ${ }^{125}$ I albumin and FITC} dextran and absorbed ${ }^{131} I$ albumin

The samples of plasma, lavage fluid, and tracheal tissue were weighed. The activities of ${ }^{125} I$ and ${ }^{131} \mathrm{I}$ were counted in a well counter (Harshaw). The detector was connected to a dual channel analyser (LEAB) and computer. Samples from each animal were counted for 60 seconds. The propagation of ${ }^{125} \mathrm{I}$ activity into ${ }^{131}$ I was less than $0 \cdot 1 \%$ whereas the propagation of ${ }^{131} \mathrm{I}$ activity into ${ }^{125} \mathrm{I}$ was about $20 \%$. To avoid the influence of scattered radiation therefore the activity of ${ }^{131}$ I was counted first and the activity of ${ }^{125} \mathrm{I} 20$ days later (the half lives are: ${ }^{131}$ I eight days, ${ }^{125}$ I 60 days). FITC dextran in samples of plasma, tracheal lavage fluid, and control solutions were analysed by fluorimetry (Perkin Elmer LS-5).

\section{Calculations}

The exudation of plasma was calculated by dividing the plasma tracer values for lavage and $50 \mathrm{mg}$ tracheal tissue samples by the values in 
$1.0 \mathrm{~g}$ plasma. Exuded plasma was expressed in microlitres of plasma in $50 \mathrm{mg}$ of tracheal tissue and recovered lavage fluid with reference to the corresponding plasma tracer. The density of plasma was set at $1 \cdot 0$. The absorption of ${ }^{131} I$ albumin was calculated by dividing the radioactivity in $1.0 \mathrm{~g}$ of plasma by that obtained in samples of the superfusate, expressed as a fraction of the total amount of activity superfused through the tracheal catheter. The amount of ${ }^{131} \mathrm{I}$ albumin was also determined in $50 \mathrm{mg}$ tracheal tissue samples.

\section{Stability of the tracers}

Intravenous ${ }^{131} \mathrm{I}$ albumin is stable in the guinea pig tracheal superfusion model during the course of the experiment both in the circulation and after exudation into the airway lumen. ${ }^{3}$ We used the same gel filtration technique (Sephadex G25, Pharmacia, Uppsala, Sweden $)^{3}$ to examine the binding of ${ }^{131} I$ to albumin both in the superfusate (containing ${ }^{131} \mathrm{I}$ albumin, DOSS $0.28 \mathrm{nmol}$, and ethanol $0 \cdot 17$ $\mu \mathrm{mol})$ and, after its absorption, in plasma recovered 10 minutes after the tracheal superfusion $(n=4)$. Samples of the superfusate (containing about $5 \times 10^{5}$ counts $/ \mathrm{min}$ ) and $1 \mathrm{ml}$ plasma (containing 700-900 counts $/ \mathrm{min}$ ) diluted in saline were filtrated. The mean ${ }^{131} I$ activity detected in the albumin fractions of the lavage fluid and the plasma samples was $93 \%$ (SE $(3 \%)$ ) and $98 \%(1 \%)$. FITC dextran is stable during prolonged in vitro and in vivo experiments. ${ }^{13}$

\section{TRACHEOBRONCHIAL DISTRIBUTION OF THE SUPERFUSATE AND ABSORPTION OF ${ }^{99 \mathrm{~m}}$ TC DTPA Tracheobronchial administration of ${ }^{99 m}$ Tc DTP $A$ and active agents}

Ten minutes after tracheal catheterisation the animals were inclined to a $45^{\circ}$ angle (head up) and positioned under a gamma camera. The surface of the tracheal mucosa was superfused with solutions $(40 \mu \mathrm{l})$ delivered at a constant rate over two minutes. The solutions contained ${ }^{99 \mathrm{~m}}$ Tc DTPA (about $8 \mathrm{MBq}$ ) in saline and histamine $(5.0 \mathrm{nmol})$, ethanol $(0.17 \mu \mathrm{mol})$, and DOSS $(0.28 \mathrm{nmol})$ plus (ethanol $0.17 \mu \mathrm{mol}$ ) or saline control. After superfusion the tracheal catheter was withdrawn and the animals were kept in the inclined position for measurement of the disappearance of ${ }^{99 \mathrm{~m}}$ Tc DTPA. Each group contained six animals.

Exuded plasma $(\mu l)$ in tracheal lavage fluid calculated from the detection of fluorescein isothiocyanate conjugated (FITC) dextran and ${ }^{125}$ I albumin

\begin{tabular}{lllll}
\hline & \multicolumn{4}{l}{ Mean $($ SEM) exuded plasma $(\mu l)$} \\
\cline { 2 - 5 } Method: & Control & Histamine & Ethanol & DOSS plus ethanol \\
\hline FITC dextran & $0.13(0.04)$ & $1.31(0.38)^{\star \star}$ & $0.76(0.25)^{\star}$ & $9.55(1.53)^{\star \star \star}$ \\
125I albumin & $0.15(0.04)$ & $1.57(0.41)^{\star \star}$ & $0.80(0.23)^{\star}$ & $8.11(1.66)^{\star \star \star}$ \\
\hline
\end{tabular}

Histamine, ethanol, and dioctylsodium sulphosuccinate (DOSS) plus ethanol caused significant exudation of plasma. Comparisons are made with saline control data $\left({ }^{\star} p<0.05,{ }^{\star \star} p<0.01\right.$, $\star \star \star p<0.001$. Student's $t$ test). There was a high correlation between individual measurements of FITC dextran and ${ }^{125}$ I albumin.
Distribution of the superfusate and absorption of ${ }^{99 m}$ Tc DTP $A$

The distribution and absorption (disappearance) of ${ }^{99 \mathrm{~m}} \mathrm{Tc}$ DTPA were monitored continuously for 20 minutes with a gamma camera (Portacamera, General Electric) equipped with a converging collimator. Images were obtained in successive one minute frames and stored in a $64 \times 64$ image matrix. A region of interest was selected over the tracheobronchial airways. Time-activity curves were generated and the half life of disappearance was calculated after a monoexponential equation had been fitted to the experimental data by the least squares method. A region of interest was also selected just proximal to the instillate to assess transport of the administered tracer by mucociliary activity.

\section{DRUGS}

The anaesthetics were ketamine (Ketalar 50 $\mathrm{mg} / \mathrm{ml}$, Parke-Davies), xylazine (Rompun vet $20 \mathrm{mg} / \mathrm{ml}$, Bayer), and pentobarbital (Mebumal vet $60 \mathrm{mg} / \mathrm{ml}$, Nordvacc). The tracers were ${ }^{125} \mathrm{I}$ and ${ }^{131} \mathrm{I}$ labelled human serum albumin (Disab), fluorescein isothiocyanate conjugated dextran (Bioflor), and ${ }^{99 \mathrm{~m}}$ Tc DTPA (Amersham International). The chemicals were guinea pig serum albumin, histamine, and dioctylsodium sulphosuccinate (Sigma).

\section{ANALYSIS}

Analysis of variance was used to examine the differences in exuded plasma tracer levels $\left({ }^{125} \mathrm{I}\right.$ albumin and FITC dextran), absorbed ${ }^{131}$ I albumin levels, and half lives of the ${ }^{99 \mathrm{~m}} \mathrm{Tc}$ DTPA time-activity curves. If changes were statistically significant further analyses were carried out with Student's $t$ test for unpaired observations. Values of $p$ less than 0.05 were considered significant (two tailed test). A regression analysis of individual values was used to examine the correlation between measurements of lavage fluid plasma as determined by ${ }^{125} \mathrm{I}$ albumin and by FITC dextran. Values are presented as means with standard errors in parentheses.

\section{Results}

\section{PLASMA EXUDATION}

Histamine, ethanol, and DOSS plus ethanol produced significant exudation of plasma into the tracheal tissue and lumen (table, fig 1). There was a high correlation between ${ }^{125} \mathrm{I}$ albumin and FITC dextran in the lavage samples $(r=0.94)$.

\section{${ }^{131}$ I ALBUMIN ABSORPTION}

Histamine did not increase the absorption of

${ }^{131}$ I albumin into the circulation. In contrast, ethanol increased the absorption of ${ }^{131} I$ albumin and this effect was much greater with DOSS dissolved in ethanol (fig 2). The content of ${ }^{131} I$ albumin in the tracheal tissue samples was only marginally affected by these treatments. The tissue levels (expressed as the fraction $\times 10^{-3}$ of the total amount of instilled activity detected in $50 \mathrm{mg}$ tracheal tissue) were: control $6.4(1.9)$, 


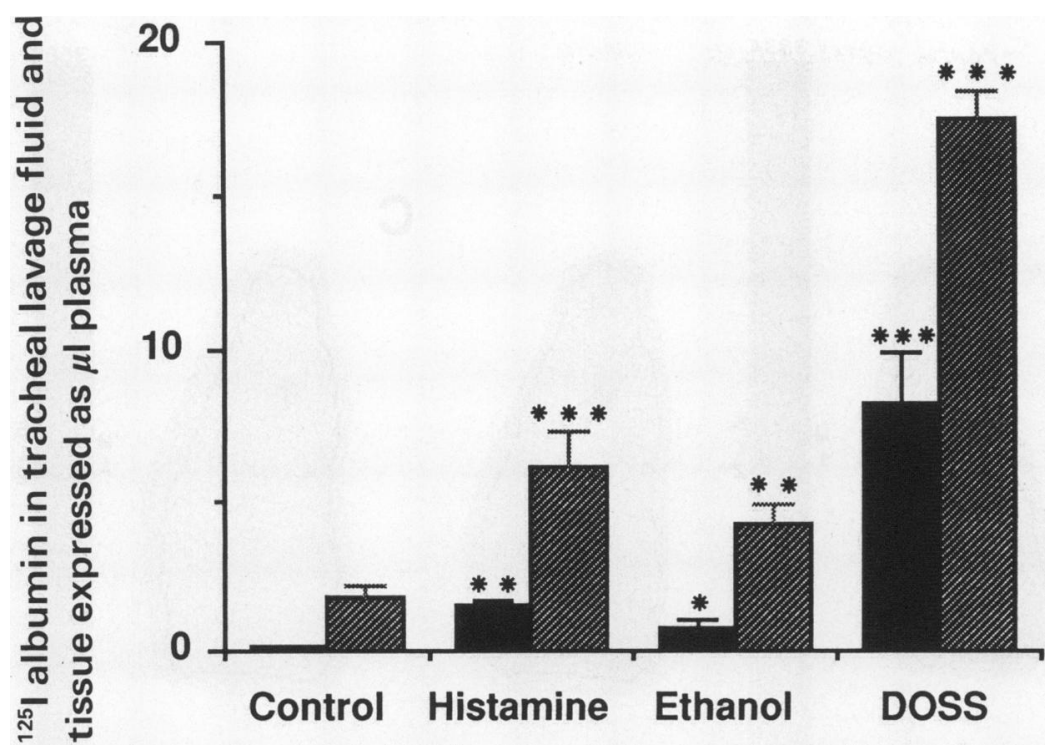

Figure $1{ }^{125}$ I albumin recovered in tracheal lavage fluid (solid columns) and $50 \mathrm{mg}$ tracheal tissue (hatched columns) after control, histamine, ethanol and dioctylsodium sulphosuccinate (DOSS). ${ }^{\star} p<0.05,{ }^{\star \star} p<0.01,{ }^{\star \star \star} p<0.001$ (comparisons with control values).

histamine $10.0(2.4)(\mathrm{p}>0.05)$; ethanol: $6 \cdot 8$ $(2 \cdot 8)(\mathrm{p}>0.05)$; and DOSS plus ethanol: $5 \cdot 7$ $(1.5)(\mathrm{p}>0.05)$. The comparisons are made with the controls.

\section{TRACHEOBRONCHIAL DISTRIBUTION AND ${ }^{99 \mathrm{~m}}$ Tc DTPA ABSORPTION}

Monitoring of ${ }^{99 \mathrm{~m}}$ Tc DTPA indicated a local and, during the course of the experiment, well defined distribution of the fluid in the trachea and proximal bronchi. Neither histamine nor ethanol altered the distribution of the boli (fig 3); DOSS plus ethanol largely maintained the same distribution of the boli but there was some diffusion upwards in the trachea immediately after its administration (fig 3 ). With a test area selected over the gastrointestinal tract we could not detect any swallowed activity in any experiment. Some displacement of activity

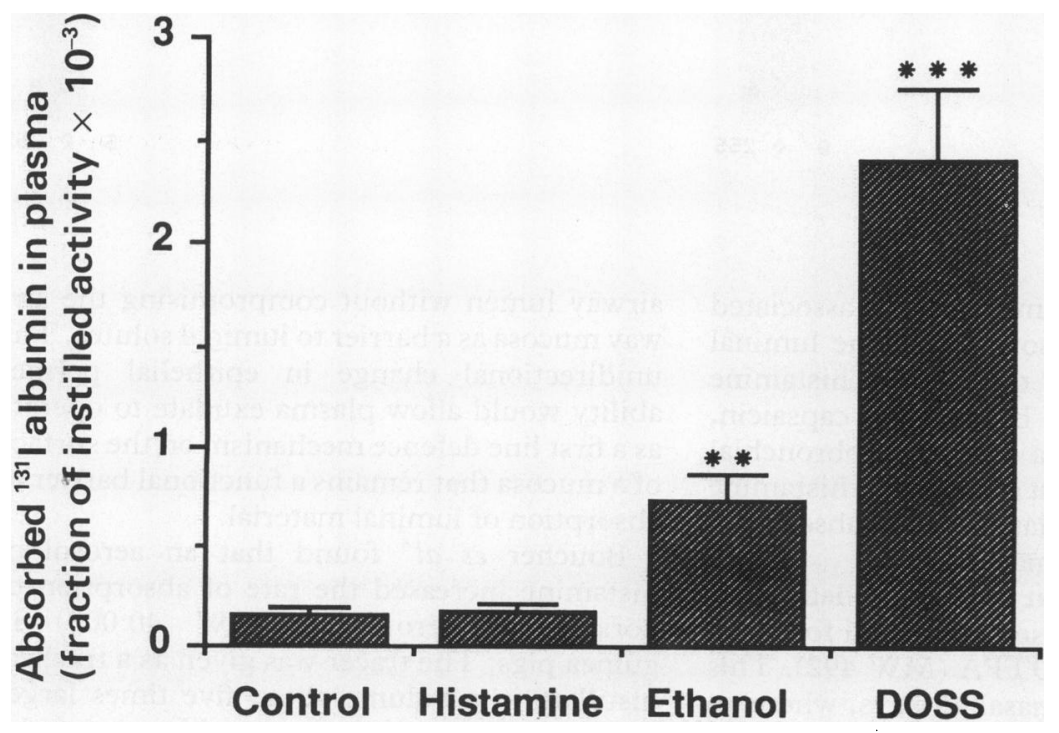

Figure 2 Absorption of ${ }^{131} \mathrm{I}$ albumin into circulating plasma $(1.0 \mathrm{~g})$, expressed as a fraction of the total activity superfused on to the mucosal surface, after control, histamine, ethanol, and dioctylsodium sulphosuccinate (DOSS). ${ }^{\star \star} p<0.01$, $\star \star \star p<0.001$ (comparisons with control values). to the oesophagus cannot, however, be excluded. The count rate over the instillate decreased with time but there was no visible change in the shape of the boli in either group. In the group receiving DOSS plus ethanol diffuse tissue background activity appeared, and radioactivity could be seen to accumulate in the bladder. No proximal transport of the superfusate in the trachea was detected. The retention curves obtained after treatment with saline, histamine, and ethanol were similar ( $p>0.05$, analysis of variance), whereas the absorption of ${ }^{99 \mathrm{~m}}$ Tc DTPA was much increased in the group given DOSS and ethanol $(\mathrm{p}<$ 0.001 , comparison with results for saline) (fig $4)$. The half lives of the tracer in the airways were: control $58.6(4.5)$, histamine $55.4(3.3)$, ethanol $55 \cdot 7(4 \cdot 1)$, DOSS plus ethanol $6 \cdot 4(1 \cdot 0)$ minutes.

\section{Discussion}

By using ${ }^{99 \mathrm{~m}}$ Tc DTPA and external gamma camera detection we have confirmed previous observations $s^{391217}$ that the primary distribution of the tracheal superfusate is confined to the central airways and that the agents in the superfusate that caused exudation did not change this distribution appreciably during the experiment. Our present superfusion technique thus permits the administration of controlled doses of agents to a rather well defined area of the tracheobronchial mucosal surface. A further aspect of the present method is that both the provoking agent and the absorption tracer were given in the same superfusate, thus ensuring that they have a similar airway distribution.

Only small amounts of the exudation tracers FITC dextran and ${ }^{125} \mathrm{I}$ albumin were found in the airway lumen of control animals. This result agrees with previous findings, showing also that none of the larger plasma tracer, ${ }^{131} I$ fibrinogen, entered the airway lumen. These data confirm the non-traumatic nature of the techniques we used for the mucosal challenge and subsequent retrieval of mucosal surface liquids. ${ }^{3}$ We have previously shown that after circulation in plasma and exudation into the airway lumen over 25 minutes the binding of ${ }^{131}$ I to albumin is at least as tight as it was in the standard solution injected intravenously. ${ }^{3}$ The present gel filtration results show equally good stability for ${ }^{131} \mathrm{I}$ albumin after it had been superfused on the airway mucosal surface and absorbed into the circulation.

Histamine increases exudation of plasma into the airway lumen in a dose dependent manner. ${ }^{3}$ This exudation with histamine $(5 \cdot 0$ nmol) has now been confirmed with both charged ( ${ }^{125} \mathrm{I}$ albumin) and uncharged (FITC dextran) plasma tracers. The close correlation between the two tracers in the exudate (table) confirms previous data, ${ }^{23}$ and support the view that the entry of albumin into the airway lumen in response to inflammation is largely an unfiltered flow of plasma across the airway endothelial-epithelial barriers rather than a secretory event. ${ }^{23}$

The 10 fold increase in ${ }^{125} \mathrm{I}$ albumin exuda- 
Figure 3 Gamma camera visualisation of the ${ }^{99 m} T c$ $D T P A$ superfusate in guinea pig

tracheobronchial airways. The dark areas show the distribution of ${ }^{99 m} T C$

DTP $A$ in the

tracheobronchial airways immediately after the superfusion (left panels) and after 20 minutes (right panels) in groups receiving saline $(A)$, histamine $(B)$, ethanol (C), and dioctylsodium sulphosuccinate (DOSS) plus ethanol (D). The surrounding line shows the contour of the animal. $A$ diffuse tissue background gradually appeared in all groups, especially the group receiving DOSS

plus ethanol; but there was essentially no change in shape of the airway boli. The animals receiving DOSS plus ethanol (D) showed pronounced radioactivity in the bladder after 20 minutes.
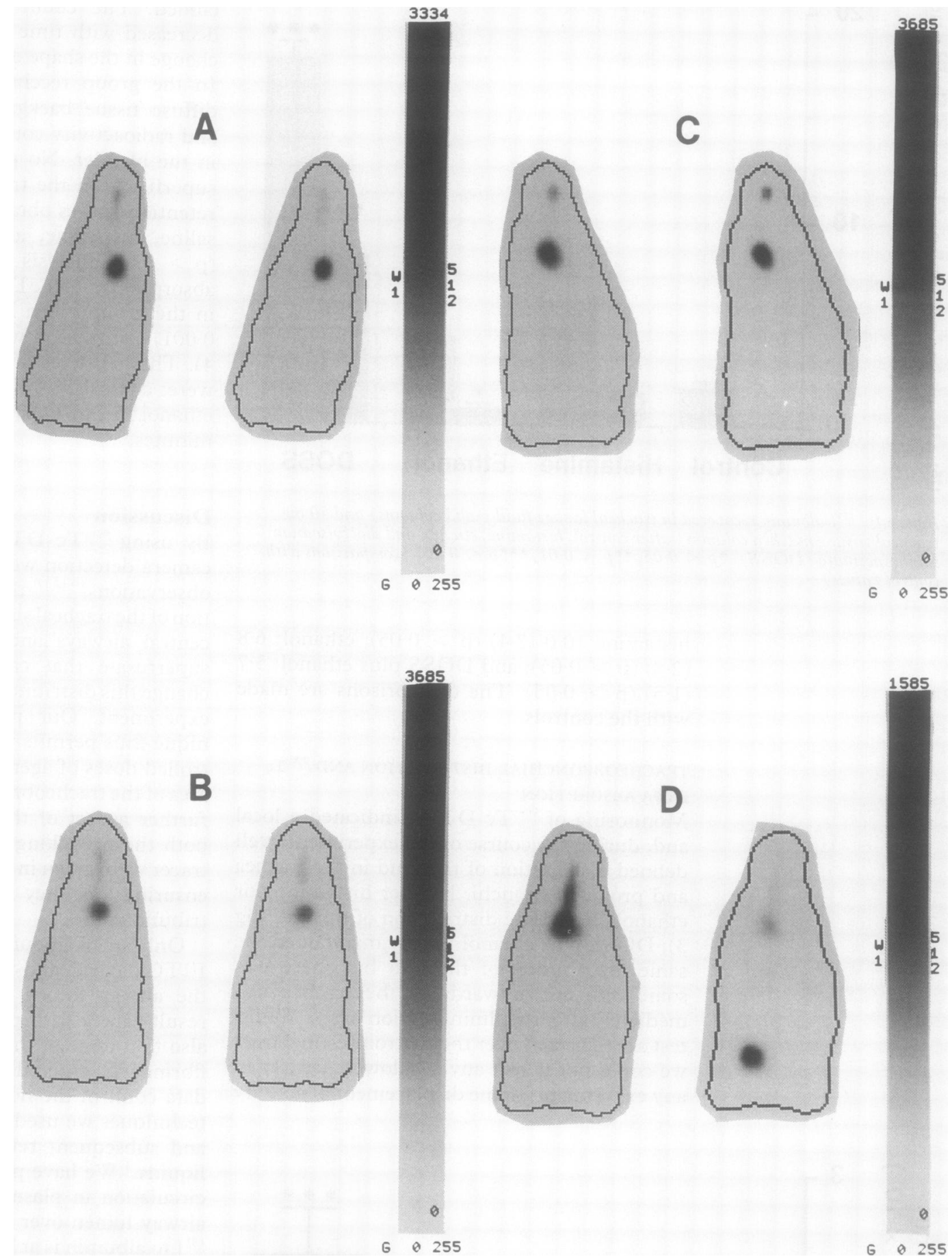

tion in response to histamine was not associated with any increased absorption of the luminal ${ }^{131}$ I albumin tracer. In this respect histamine mimicks the action of bradykinin, capsaicin, and allergen in guinea pig tracheobronchial airways. ${ }^{9}$ This is the first study to use histamine and to employ exudation and absorption tracers in the same animal.

Our study shows that during exudation the absorption barrier is also maintained for small solutes such as ${ }^{99 \mathrm{~m}}$ Tc DTPA (MW 492). This also occurs in human nasal airways, where an exudative dose of histamine had no effect on the absorption of ${ }^{51} \mathrm{Cr}$ EDTA (MW 372). ${ }^{15}$ It may be a general property of endogenous exudative mediators to enable exuded plasma to enter the airway lumen without compromising the airway mucosa as a barrier to luminal solutes. The unidirectional change in epithelial permeability would allow plasma exudate to operate as a first line defence mechanism on the surface of a mucosa that remains a functional barrier to absorption of luminal material.

Boucher et $a l^{5}$ found that an aerosol of horseradish peroxidase (MW 40000 ) in guinea pigs. The tracer was given as a tracheal instillate in a volume about five times larger than the present superfusate. More recently, Ranga et $a l^{7}$ found less consistent effects of peroxidase from guinea pig lower airways, but histamine increased the rate of absorption of allergen on the absorption of horseradish 


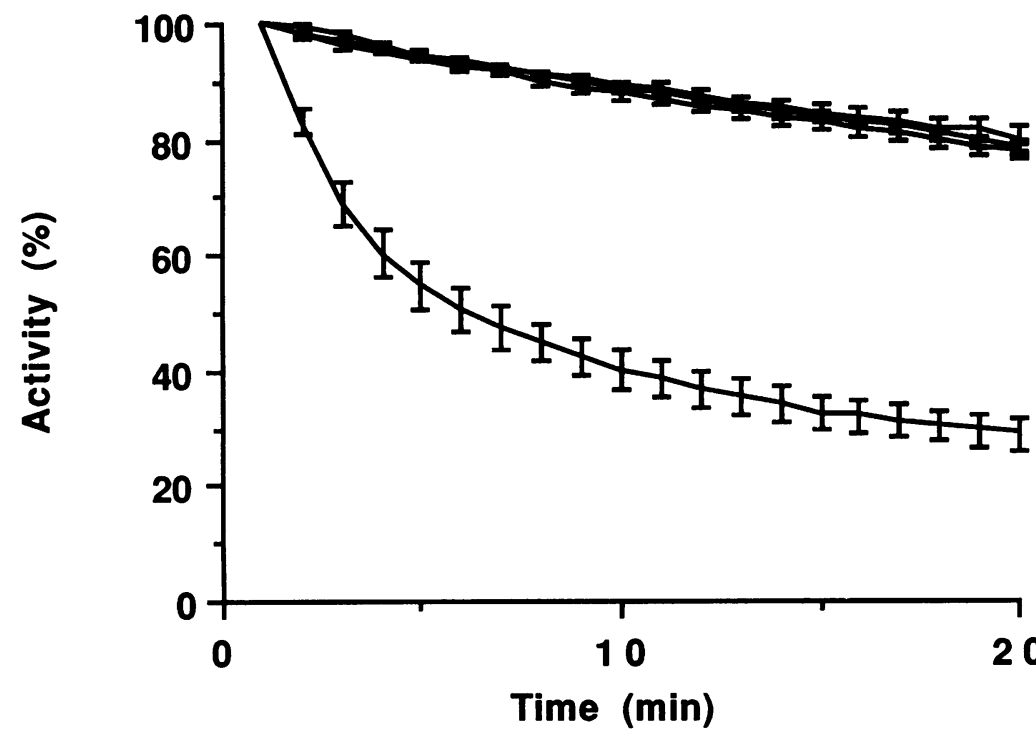

Figure 4 Time-activity curves from the tracheobronchial airways of animals receiving saline, histamine, ethanol (upper three lines), and dioctylsodium sulphosuccinate (DOSS) plus ethanol (lower line).

concluded that absorption was increased. As the airway distribution of histamine, allergen, and horseradish peroxidase in these studies is unknown, making direct comparisons with the present findings is difficult. When we used our superfusion technique to administer a muscarinic agonist (carbachol) together with an absorption tracer we could not confirm the report that muscarinic agonists increase the absorption permeability of the airways. ${ }^{5}$ Thus our present and previous data ${ }^{9}$ suggest that neither mediators that cause exudation (histamine, bradykinin, capsaicin, and allergen) nor those that do not (muscarinic agents) increase tracheobronchial absorption of luminal solutes.

Histamine is an endogenous agent that may be released in airway defence operations, ${ }^{8}$ whereas DOSS and ethanol may be considered as agents with non-specific toxic effects on the airway mucosa. DOSS may be similar in its action to large doses of another detergent, lysophosphatidylcholine, which is known to cause severe damage to the mucosa. ${ }^{18}$ In our study ethanol, used as a vehicle for DOSS, caused exudation of plasma. It also increased the absorption of ${ }^{131}$ I albumin but did not affect the rate of disappearance of ${ }^{99 \mathrm{~m}} \mathrm{Tc}$ DTPA, indicating that it may increase macromolecular absorption across the mucosa specifically in addition to causing exudation of plasma. The mechanism underlying the present size dependent permeability changes remains unknown, but a distinction between small and large solute permeability has previously been observed in intestinal mucosa. ${ }^{19}$ DOSS (given with ethanol) caused pronounced increases in both the exudation (outward) and absorption (inward) permeabilities of the airway mucosa. Three patterns of changes in the mucosal barrier functions were thus recorded: histamine producing exudation without increasing absorption, ethanol producing exudation and selectively increasing large solute absorption, and DOSS plus ethanol producing massive exudation and large increases in small and large solute absorption. The tissue response common to the three provoking stimuli was exuda- tion of plasma, which is consistent with the view that this response is a primary defence mechanism. ${ }^{8}$ Further studies are warranted to determine the mechanisms concerned in the abnormalities of increased airway absorption observed with ethanol and DOSS.

In conclusion, this study has shown that histamine produces exudation of plasma into the airway lumen with no concomitant increase in the absorption of small and large solutes from the lumen. This appears to be a specific action of endogenous mediators because toxic inflammatory factors produced changes in the absorption permeability of the mucosa in addition to increased exudation. These observations support the view that a main purpose of autacoid induced plasma exudation responses in the airways is to allow the potent protein systems of plasma to carry out defence operations on the surface of an intact airway mucosa.

This study was supported in part by grants from the Swedish Medical Research Council (projects 8308 and 2872), the Swedish Association Against Heart and Chest Diseases, and the Torsten and Ragnar Söderberg Foundation.

Persson CGA. Role of plasma exudation in asthmatic airways. Lancet 1986; ;i:1126-9.

2 Persson CGA, Erjefält I. Inflammatory leakage of macromolecules from the vascular compartment into the tracheal lumen. Acta Physiol Scand 1986;126:615-6.

3 Erjefält I, Persson CGA. Inflammatory passage of plasma macromolecules into airway wall and lumen. Pulm Pharmacol 1989;2:93-102.

4 Leskowitz S, Salvaggio JE, Schwartz HJ. An hypothesis for the development of atopic allergy in man. Clin Allergy 1972;2:237-42.

5 Boucher RC, Ranga V, Paré PD, Inoue S, Moroz LA, Hogg JC. Effect of histamine and methacholine on guinea pig tracheal permeability to HRP. J Appl Physiol 1978;45: 939-48.

6 Hogg JC. Bronchial mucosal permeability and its relationship to airway hyperreactivity. J Allergy Clin Immunol 1981;67:421-7.

7 Ranga V, Powers MA, Padilla M, Strope GL, Fowler L, Kleinerman J. Effect of allergic bronchoconstriction on airways epithelial permeability to large polar solutes in the guinea pig. Am Rev Respir Dis 1983;128:1065-70.

8 Persson CGA, Erjefalt I, Alkner U, Baumgarten C, Greiff L, Gustafsson B, et al. Plasma exudation as a first line respiratory mucosal defence. Clin Exp Allergy 1990; 21:17-24.

9 Erjefält I, Persson CGA. Allergen, bradykinin, and capsaicin increase outward but not inward macromolecular permeability of the guinea pig tracheobronchial mucosa. Clin Exp Allergy 1991;21:217-24.

10 Persson CGA, Erjefält I, Gustafsson B. Subepithelial hydrostatic pressure may regulate plasma exudation across the mucosa. Int Arch Allergy Appl Immunol 1990; 92:148-53.

11 Gustafsson B, Persson CGA. Asymmetrical effects of increases in hydrostatic pressure on macromolecular movement across the airway mucosa. Clin Exp Allergy movement acro

12 Persson CGA, Erjefält I, Andersson P. Leakage of macromolecules from guinea pig tracheobronchial microcirculation. Effects of allergen, leukotrienes, tachykinins, and anti-asthma drugs. Acta Physiol Scand 1986;127: 45-105.

13 Luts A, Sundler F, Erjefalt I, Persson CGA. The airway epithelial lining in guinea pigs is intact promptly after the mucosal crossing of large amount of plasma exudate. Int mucosal crossing of large amount of plasma

14 Svensson C, Baumgarten CR, Pipkorn U, Alkner U, Persson CGA. Reversibility and reproducibility of histamine induced plasma leakage in nasal airways. Thorax 1989; 44:13-8.

15 Greiff L, Wollmer P, Pipkorn U, Persson CGA. Absorption of ${ }^{51} \mathrm{Cr}$ EDTA across the human nasal airway barriers in the presence of topical histamine. Thorax 1991;46:000-00.

16 Hart MV, Rowles JR, Hohimer AR, Morton MJ, Hosenpud JD. Hemodynamics in the guinea pig after anesthetization with ketamine/xylazine. American Journal of Veterinary Research 1984;45:2328-30.

17 Greiff L, Wollmer P, Eriefält I, Pipkorn U, Persson CGA Clearance of ${ }^{99 \mathrm{~m}}$ Tc-DTPA from guinea pig nasal tracheobronchial and bronchoalveolar airways. Thorax 1990;45: $841-5$

18 Lindahl M, Hede AR, Tagesson C. Lysophosphatidylcholine increases airway and capillary permeability in the isolated perfused rat lung. Exp Lung Res 1986;11:1-12.

19 Weström BR, Tagesson C. Low molecular weight tracers do not reflect intestinal macromolecular permeability. J Pedriatr Gastroenterol Nutr 1989;8:422. 